\title{
Blanchot y la lógica de la desapropiación
}

\section{Blanchot and the Logic of Unappropriation}

\author{
Guillermo Sergio Espinosa Proa \\ Universidad Autónoma de Zacatecas, México \\ sproa52@hotmail.com
}

Resumen: Frente a Hegel y la dialéctica, algunos autores como Maurice Blanchot contraponen la amistad como relación humana esencial y la experiencia estética como paradigma de la acción, relegando el trabajo, que es servil siempre, como modelo decaído de la misma. En este ensayo se ahonda en la cuestión privilegiando dos textos, aparecidos en I969 y I97 I, en donde Blanchot se plantea explícitamente la diferencia entre la dialéctica y la tragedia como formas antitéticas de plantear la realidad de lo humano y su presunta superación.

Palabras clave: Blanchot, arte, trabajo, dialéctica, tragedia.

Abstract: In contrast to Hegel and dialectics, some authors such as Maurice Blanchot oppose friendship as an essential human relationship and the aesthetic experience as a paradigm of action, relegating work, which is always servile, as a decadent model of it. In this essay, the question is explored in depth by giving priority to two texts, which appeared in I969 and I97I, in which Blanchot explicitly poses the difference between dialectics and tragedy as antithetical ways of posing the reality of the human and its alleged overcoming.

Keywords: Blanchot, Art, Work, Dialectics, Tragedy. 
Recibido: 23 de febrero de 2020

Aceptado: Io de junio de 2020 https://dx.doi.org/I O.I 5 I 74/rv.vi 3i27.533

Si no media el deseo de apropiación, ni el afán de consumo, $\checkmark$ ¿qué relación cabría esperar con las cosas (y las personas)? Una relación que apenas será relación; el modelo es, desde luego, la amistad. Un apego sin posesión, una cercanía sin confusión -ni imitación-. Es la relación que sostiene el lazo del afecto evitando que este se transforme inadvertidamente en dependencia o sujeción. Pensemos así en la distancia perfecta. Filosófica es la amistad con la sabiduría, pero, ¿de qué podría ser amigo el arte? Si lo que nos humaniza, según la antropología, es el lenguaje articulado -y no la técnica-, ¿no es la fuerza poética de invención del mundo lo que se halla en el principio de todo? Y si es así, ¿cómo habitar una tierra desprovista con toda evidencia de facultad semejante? ¿Cómo sobrellevar esta prodigiosa soledad? Ni la dominación ni la explotación de la tierra son maneras exclusivas de asentamiento; la vida de un animal que habla se expande, se complica, se multiplica sin límites visibles: florece, echa raíces. La línea divisoria entre naturaleza y cultura es, lo sabemos, la presencia o ausencia de una "función simbólica"sobre la que todo lenguaje se sostiene. ¡Solo que nada puede saberse de su origen! De pronto, todo significa; un instante antes, nada. ¿Ocurre lo mismo en el arte?

Maurice Blanchot se admira de la cueva de Lascaux (y del texto que a ella dedica Bataille): el nacimiento del arte es la afirmación pura de su perpetuo nacimiento (Blanchot, 2011: 11). Lo admirable es que en esas pinturas "el arte surge visible e impetuosamente de la noche", y que, menos que a una contemplación desinteresada, invita a una extática comunión. Blanchot se pregunta 
si tal comunión no reproduce el vínculo de "casi amistad"que sus creadores -cazadores de renos, antílopes, megaterios y mastodontes- mantenían con la naturaleza. El arte es la fiesta de su propia existencia: no el momento de reposo y reflexión, sino la exaltación de la vida que sobreviene y se contrapone al trabajo civilizatorio: las pinturas de Lascaux pertenecen:

a ese movimiento de efervescencia, a esa generosidad explosiva de la fiesta, cuando, interrumpiendo el tiempo del esfuerzo y del trabajo, el hombre -entonces por vez primera verdaderamente hombre-, en el júbilo de un breve intermedio, vuelve a las fuentes de la sobreabundancia natural, a lo que era cuando todavía no era, hace trizas las prohibiciones, pero, por el hecho de que ahora las hay y de que las quebranta, se exalta por encima de la existencia de origen, se une a ella dominándola, le da el ser dejándola ser (13).

Que con el arte el hombre llegue "por primera vez" a ser hombre es una lanza, una jabalina incrustada en el costado del materialismo vulgar, ese según el cual la humanidad es un efecto de la técnica, es decir, de una transformación consciente y racional del medio a fin de satisfacer necesidades básicas; no, lo humano no es efecto del trabajo, como quería la filosofía (y la economía política) moderna, sino su -jubilosa- interrupción. Porque humana es la derrota de la naturaleza -exterior e interior-, mas también lo es el desamparo y el terror que a semejante victoria de la astucia acompańan. ¿Habría otro origen del arte? Cada conquista en un plano nos ha debilitado en otro, o en otros: es la conciencia del fracaso lo que nos vuelve humanos; eso, y la imposibilidad de retornar a una existencia puramente instintiva. En breve: humana es la ley y su transgresión, la prohibición y su desobediencia. ¿Qué les hizo falta a los neanderthales? "Conocer la ley mediante la infracción soberana”, sospecha el escritor (15). La hipótesis de Blanchot sigue 
de este modo la senda abierta por Bataille (que antes ha movilizado a Hegel contra sí mismo): de la naturaleza a la cultura no hay uno sino dos saltos. El primero, la autolimitación, la prohibición, la salida del estado de naturaleza, la autodomesticación; el segundo, la fastuosa suspensión de los interdictos, la vuelta a la libérrima inmensidad del ser. Constricción/desconstricción: trabajo/fiesta. Una vez más: civilización versus cultura.

Veámoslo en el caso directo de la aparición del arte.

\section{II}

Lo humano nace con el arte; antes de él existen bocetos, borradores, líneas punteadas, muñones. Entre el homo faber y el homo aisthethicum media un abismo. Definirse por el trabajo equivale, muy hegelianamente, a decidir que nuestro ser esencial es la negación (determinada o indeterminada) de lo existente; definirse por la fiesta significa, más acá de Hegel, saber que nuestro ser es el lujo, el suplemento, el azar, la afirmación, la gratitud y la gracia: un ser humano celebra y no solo lucha, está hecho de exaltación y no solo es un saco de lamentaciones. Muy por encima de la productividad está la creatividad -e incluso la inacción, la contemplación pura-. ¿Cómo concebir el antes de la concepción, el vacío que la hace posible? "El arte", escribe Blanchot, "está siempre vinculado al origen, referido este siempre al no-origen; explora, afirma, suscita, en un contacto que conmueve toda forma adquirida, todo lo que está esencialmente antes, lo que es sin ser todavía. Y, al mismo tiempo, se adelanta a todo lo que ha sido; es la promesa cumplida de antemano, la juventud de lo que siempre comienza y no hace sino comenzar"(18). Como animal de trabajo, el hombre se ha abierto paso a través de eones de impensable hostilidad; es por su prolongado y dolorido combate que nosotros mismos hemos podido llegar a la existencia. Pero solo con esa afirmación gozo- 
sa, gloriosa, que se percibe sin regateos en las cavernas pintadas a la vacilante luz de una antorcha hace treinta mil años, podemos sentir o presentir a la humanidad en estado naciente. Solo ahí hay un sentimiento de parentesco e incluso de fraternidad: no hace mucho tiempo que andamos por aquí.

Es con seguridad lo que permite a Blanchot escribir estas palabras, no exentas de (juvenil) entusiasmo:

lo que sugieren los primeros grandes momentos del arte es que el hombre no tiene contacto con su propio comienzo, no es afirmación inicial de él mismo, expresión de su propia novedad más que cuando, por medio y por las vías del arte, entra en comunicación con la fuerza, el esplendor y el dominio alegre de un poder que es esencialmente poder de comienzo, es decir, también de recomienzo previo (19).

Esta hipótesis, acaso simple conjetura, tiene un alcance inmenso. Semihumana es la separación (técnica) de la naturaleza; humano, el movimiento (estético-religioso) de vuelta al origen, de rememoración o reminiscencia de lo anterior. Se llega a ser humano no solo por aseguramiento y acumulación, sino, más profundamente -e irreversiblemente-, por despojamiento: desnaturalización civilizatoria, renaturalización cultural. ¿Hasta qué punto y cómo sería refrendable esta anterioridad? Decisivo será, por principio de cuentas, distinguir entre refrendo y recuperación; la obra no es, propiamente, encarnación del tiempo perdido. Proust es el primero en saberlo: su novela es la busca, no la captura del tiempo perdido. Es lo propio de la obra: en su aparecer conlleva un desaparecer, un fugaz rechazo de la permanencia. Niega la nada de la que emerge, pero lo hace logrando que la nada pose su mirada en nosotros (43). No toda negación es una afirmación, pero toda afirmación supone una negación. En el caso de la obra, la afirmación 
de sí implica una negación del mundo: el arte ni siquiera existe a fin de ser admirado (en el arte paleolítico eso está claro). El arte es una afirmación del tiempo, no su negación. Quizás, pero ¡en qué podría consistir una afirmación del tiempo si no en la negación de la eternidad (y la necesidad) de lo presente? Hay en esta instantaneidad de lo eterno toda una filosofía de la obra, toda una antropología del arte. A fin de convertirse en obra, la condición es eludir todo condicionamiento, despojarse de toda servidumbre. El arte aparece así como la esencia (desapercibida) de la religión: los dioses son máscaras, sublimaciones de ese poder de afirmación de la vida en su fugacidad -y en su deslizamiento hacia el origen, que es la muerte. "Por ello, el arte va unido a todo lo que pone al hombre en peligro, a todo lo que le sitúa violentamente fuera del mundo"(37). Y esto, ¿qué relación guardaría con la religión?

\section{III}

Incordiando a Hegel, diremos que la religión es una manifestación imperfecta y atrofiada del arte: este es, según vamos viendo, la afirmación incondicional de la existencia en su carácter temporal. Un absoluto ni siquiera negativo: decididamente neutro. En términos ontológicos, la presencia solo puede afirmarse afirmando a la vez la ausencia, la ausencia de mundo, la ausencia de ardides y acrobacias para asegurarse en el mundo, la ausencia de trucos y ensueños para afirmar una eternidad de la presencia. La obra se presenta, así, en el hueco de la ausencia, lo que significa que la existencia emerge de una nada que nada deshabilita o disipa de una vez por todas. ¡Es lo contrario de la religión, o al menos de la religión entendida como anhelo de salvación y presencia perpetua del sí mismo! La argumentación de Blanchot en "El museo, el arte y el tiempo"es vertiginosa; parece hecha para mostrar el hormigueante o agusanado reverso de Hegel: el único sentido de la Fenomenología del 
espíritu es la disolución en acto del sentido -de un sentido trascendente-. ¿Nihilismo? En efecto, mas un nihilismo lúcidamente asumido:

la obra es su propia ausencia: a causa de esto, en perpetuo devenir, nunca perfecta, siempre hecha y deshecha [...] En el seno de esta ausencia, las obras están en perpetua disolución y en perpetuo movimiento, no siendo cada una más que un hito del tiempo, un momento del todo, momento que, sin embargo, querría, y desesperadamente, ser para sí solo ese todo en que solamente la ausencia descansa sin descanso. Y como este deseo es imposible, la obra misma, tomando cada vez más conciencia de esta imposibilidad, tiende cada vez más a afirmarse como un signo patético, una flecha indicadora fascinante, que apunta a lo imposible (41).

La crítica tradicional del arte carga las tintas al momento victorioso donde el artista, en el clímax de su maestría, toca la eternidad, como si esta fuera un objeto expuesto a la apropiación de los hombres. "Pero igualarse al arte es ya retornar a la ausencia y solo la ausencia es 'eternidad'". Para Blanchot, nihilista es la ambición de "negar nuestra nada", pues nada se saca de allí: es el gesto alérgico o inmunológico que no se da el tiempo de comprender que la vida es una fulguración de la muerte, de "esa sombría impotencia privada de dueño, que es la de la muerte como recomenzar"(43).

No habría que espantarse; en el fondo, es una derivación de la frase de Nietzsche: Gott ist Tot. El escritor se planta en medio de esta insufrible proliferación de obras a-la-orden que es el arte moderno: antes, bastaba con ir a un museo; hoy, desde la comodidad del sofá tenemos todo (hasta lo que no) a nuestra disposición. Internet es la realización (virtual) del tan temido Museo Imaginario de André Malraux. ¿El arte muere a manos de la técnica? Otro sueño imposible: el arte no muere porque en la obra anida la 
mortalidad, es decir, el devenir, el incesante ser-otro-de-sí. "En las obras", concluye el escritor,

comprendemos ya la infinita variedad de un conflicto que las divide, las exalta y las arruina: necesidad de estar solas y siempre encerradas en sí mismas, visibles-invisibles, sin mirada y, como dijo Rilke, separadas de nosotros por un vacío que nos aparta y las aísla; pero necesidad también de estar en relación unas con otras, necesidad de ser, cada una por sí sola y, sin embargo, todas en conjunto, la evidencia del arte, de ser únicas, pero también de ser solo el momento de un mayor devenir, volviendo para nosotros sensible, real y ya acabado el espacio de ese devenir que se realiza $\sin$ fin (48).

¿Qué es lo que se juega en todo esto? ¿Qué afirma la obra que no puede ser afirmado de ninguna otra manera? El lenguaje que sabe de sí solo sabe que con su irrigación y su floresta nada puede contra la desaparición de todas las cosas; sabe que su fuerza es absolutamente ilusoria y que, en la obra, en vez de prometer la inmortalidad en alguna de sus siempre insuficientes formas, se asiste, en un sentido casi médico, a la desaparición misma. La obra afirma el fin: un fin sin trascendencia. Lo cual nos conduce directamente al corazón de la tragedia.

\section{IV}

Maurice Blanchot habla expresamente de Grecia y de lo trágico en la parte central de su libro La conversación infinita (2008: 101-359). Son los trece capítulos que componen "La experiencia-límite"y que comienzan con Heráclito. Comienza, pues, a la mitad, pero con un verdadero comienzo. "Todo cambia a partir de Heráclito, porque todo comienza con él"(112). Lo que dice 
Heráclito no es una repetición de las leyendas mitológicas, o su recreación, como lo habría hecho Hesíodo, sino algo en verdad nuevo. Tan nuevo que no hay un lenguaje capaz de decirlo. Hay que inventarlo, y lo primero es controlar el natural y alegre deslizamiento hacia lo metafórico. El lenguaje de la filosofía es, para empezar, severo (es decir: serio). ¿Cuál sería por ventura su “tema”, si las cosas están hechas de palabras, sino la diferencia misma entre palabras y cosas? Porque quizá las palabras no quieran envolver las cosas, sino simplemente hacernos verlas.

Quizá esa sea la extrańa y novedosa encomienda de Heráclito: no decir nada que pueda cristalizar en discurso, ser como el río que, salvo su nombre, nunca es el mismo. Un buen ejemplo es la palabra del suplicante, de quien al dirigirse a los dioses crea un espacio sagrado, una zona limítrofe, un medio para la mesura. La posición de Blanchot es, en este respecto, terminante: si la palabra racional brota de la oscuridad, primero es preciso afirmar a esta. Eso le brinda al discurso un rigor propio. Tal vez en obediencia a este rigor a Heráclito siga la palabra del suplicante y a esta le siga Pascal. Un rigor no de la razón sino del corazón. En Blanchot, la razón solo es apariencia y superficie: hay que permanecer atentos al corazón de la razón, a sus latidos y síncopas. Que ello sea no imposible pero sí supremamente difícil lo da por descontado. Existe, más allá de la "medianía" de la vida cotidiana, donde se ofrece a la sensibilidad y a la inteligencia un claroscuro de bordes suavizados y como de felpa, una razón trágica consistente en la agudización resultante de la afirmación de los extremos. La probable vía de acceso es, en Pascal, similar a la súplica; como se sabe, es la apuesta. Ella equivale a una afirmación, no a una negación de lo incierto. En segundo lugar, esta afirmación no puede hacerse desde la irreflexión. ¿Doblemente lúcida? Es interesante que el escritor invoque a Pascal -y no a Sófocles o a Nietzsche- como epítome del pensamiento trágico. Porque solo existen tres modos 
del pensamiento (vivir en el mundo, tal como este se ofrece en su inmediatez, no sería pensar): la mística, la dialéctica y la tragedia. ¿Cuál es la diferencia?

Me parece muy clara: aquella que hay en fusionar, reconciliar o afirmar los extremos. Es el sentido genuino de lo neutro: ni misticismo, ni dialéctica. ¡Tragedia! Solo que tragedia en una desviación más que aguda; en ella caben la mística de Simone Weil y, en grandes tramos, la dialéctica de Hölderlin. De la primera reconocerá la dificultad esencial consistente en apartarla de un camino de santidad, no por otra cosa sino por ajustarse forzosamente a necesidades doctrinales. Weil es trágica por la discontinuidad y la infinitud a que somete su escritura. Tiene con ello que romper simultáneamente con la trascendencia y con la inmanencia. El Bien ha de ser deseado, no plantado y ni siquiera descubierto. Con lo único que debemos conformarnos es con su nombre, que resulta indiferente cuál sea, y con la formidable belleza de algunas palabras. Con eso y con el mandamiento de no confundirlo con las cosas de este mundo. La idea del Bien, es decir, más allá de teologías, la idea de Dios. ¡Simone Weil nos hace pensar en una teología trágica! De Blanchot es fascinante casi todo, pero esta capacidad de sacar agua de las piedras no tiene pérdida. ¿Cómo se puede llegar ahí si nuestro transporte es religioso y no estético? Respuesta: impidiendo una justificación banal a la idea de Bien. Ni la salvación, ni la inmortalidad personal, ni la noción de un más allá pueden servir de coartada. Si el Bien es aquello gracias a lo cual amamos, nunca será bastante la distancia que sepamos interponer con ello. El Bien no admite definición. No es "algo". Pensar que Dios "es" ya significa achicarlo al tamaño de nuestras limitaciones; por lo mismo, dice Blanchot, un ateo está más cerca de Dios que un creyente. Pero incluso no saber esto es necesario. ¡De lo contrario haremos del vacío o de la nada una condición! Aquí es cuestión de otra cosa: de fe, aunque la palabra asuste. Es la cuestión de la gracia. Weil pien- 
sa que ella se alcanza no por la felicidad sino por su contrario, la desgracia. Dios no se presenta porque sea muy "grande" o porque lo merezcamos; si viene, es porque sí. Es exactamente como la desgracia: nadie hace nada por ello y, sin preguntar o pedir permiso, simplemente llega. O no. La posición de Weil es la de una afirmación pura, aquella que no necesita ni condiciones ni justificación. Es en esa tesitura que lo de ella sigue siendo trágico, por más que el pathos no guarde relación alguna, o muy poca, con la tragedia griega antigua. ¿Afirma por algo? Todo más bien nos alejaría o nos disuadiría de tal actitud. No obstante ello, Weil nunca pierde la fe. Si hay una certidumbre absoluta, y a ella se atiene, es a su posesión de una experiencia mística. Blanchot insiste sobre ello: su afirmación no es tan pura porque "sabe" que Dios es amor. Lo ha visto. Pero, ¿por qué continúa siendo amor? Porque se le ha mostrado como lo opuesto al Dios Todopoderoso de la tradición:

No es el Todopoderoso que nuestra idolatría se apresura a adorar en él, con el fin de adorar el poder en nosotros. Él es, por el contrario, la absoluta renuncia al poder, es abdicación, abandono, consentimiento en no ser lo que podría ser, y eso tanto en la Creación como en la Pasión. Dios no puede nada para nosotros, por lo menos todo el tiempo que seamos nosotros mismos, que estemos rodeados por nosotros (146).

¿Cómo sabríamos de ello sin de algún modo ser ello mismo? Ahora tenemos que plantear el problema de la identidad del discurso blanchotiano.

\section{$\mathrm{V}$}

El trabajo de Blanchot se puede admitir tranquilamente como una alternativa real a la filosofía. A la filosofía pagana, en concreto. 
¿Cuál podría ser esa "rara exigencia" (diría su biógrafo) a la que somete el multiforme espacio del pensamiento? Arranca de la extrañeza de la literatura; una extrańeza que pronto, por decir lo menos, se convertirá en obsesión. No es descabellado afirmar que se ocupó de la literatura a raíz de su radical deslinde de cierta política (de derechas, para decirlo sin ambages). Poco a poco desembocó en ese concepto extraño "capaz de un activismo infinito" que es lo Neutro. Neutra es la creación que resulta rebelde a toda categorización y a todo consumo, a toda apropiación de un "yo". Mienta la inquietante presencia del tercero excluido, del verdadero responsable de la creación, de la figuración y de la desfiguración propias del espacio literario. "El movimiento de creación es así a la vez neutro y singular: en sus textos críticos, Blanchot tratará de atrapar la parte del neutro en cada creación singular; en sus relatos, describirá el movimiento anónimo merced al cual la prueba singular se disuelve en una experiencia indefinida" (Bident, 2003: 25). ¿Quién escribe? Ni el "yo" cartesiano ni el "se" impersonal de Heidegger; escribe lo Neutro, capaz no de constituir las singularidades pero sí, como la muerte, de atravesarlas. Otra palabra de lo Neutro es, entonces, la Muerte. Epicuro lo dijo inmejorablemente: "Si estoy yo, no está la muerte; si está la muerte, no estoy yo”. Pero mientras que el filósofo griego decide no preocuparse por ella, Blanchot, muy moderno -y encima, aunque no es seguro, judío-, opta por pensar esa impotencia fértil en que consiste la muerte. Inclusive la amistad, decisiva para él, sería una de sus formas privilegiadas. La anulación, el abandono, el borramiento, ¿no son sus medidas? Lo serían a condición de entender, como lo entiende Simone Weil (que tal vez en esto no haga más que seguir de cerca a Isaac Luria) lo divino como abdicación, como vacío. Dios no "llena" el mundo con su Creación, es al contrario: crea la nada, la extrae de sí para que haya mundo. 
Esta es la idea que el escritor detecta en Weil -y hace suya-. A fin de cuentas es el trabajo del judío de cada cultura: el éxodo, el exilio, la extrańeza, el aprendizaje (y la dependencia) del habla. Nomadismo en oposición a paganismo: el judaísmo es la errancia (o al revés). Ser judío es una contrariedad que ninguna dialéctica disuelve. Pero eso se logra mediante cierta relación con el lenguaje más que con la tierra; ser judío no es tanto haber nacido en cierto lugar sino hablar de cierta manera consigo mismo y con la divinidad. Una divinidad consistente, según Blanchot, en ser "lo infinitamente Distante" y "lo absolutamente Ajeno" (2008: 163). Ahora bien, lo esencial, para el judío, es que, a pesar de ese abismo infranqueable, Dios habla. Habla con él, con lo que la palabra se instaura como el puente entre Él y el abismo, sin anularlo. El habla es la Tierra Prometida. En ella no se trata de hacer del prójimo un igual, sino un extraño o un desconocido que es admitido en su extrañeza. Obviamente, esto ocurre en teoría, pues lo que puede darse en la práctica es una negación pura y simple. Pero, según esto, la esencia del judaísmo es la separación, el apartamiento, la diferencia, el Afuera. ¡Hablando se acoge al desconocido! Si este desconocido es una amenaza, caeremos en el racismo. Blanchot no dice que este racismo (o antisemitismo) sea "natural"; dice que es "lo más común". Su formulación es impactante: "el antisemitismo [...] representa la repulsión que inspira el Prójimo, el malestar ante todo lo que viene de lejos y de otra parte, la necesidad de matar al Otro" (165). Suprimir al prójimo por todo lo que representa y por todo lo que obliga a hacer y deshacer: eso es el nervio del antisemitismo. En nota a pie de página, el escritor anticipa una objeción obvia: ¿qué pasa con Israel? ¿El judaísmo pierde todo su sentido al hacerse de una tierra, de un país, de un Estado? En realidad, el judaísmo, menos que una nacionalidad o una etnia, es un estado del espíritu. Esto queda muy claro en el apartado subsecuente, a propósito del libro de Robert Antelme. Lo único que quiere un 
sujeto reducido, con sufrimiento, al estatuto de prójimo, es hablar. Hablar sin parar, pues es aquello que destruye la soledad. Esta polaridad de lo indestructible y lo más fácilmente destructible, desde un punto vista humano, está en Kafka. Pero es sin duda con Nietzsche que se llega a la cima; lo Neutro parece, si no otra cosa, el tope del nihilismo. Por su forma, el fragmento y la autocontradicción son inherentes a su obra: no hay centro, no hay sistema. Que su coherencia tiene otra forma y otro sentido es algo de lo que Blanchot parte; no es ni una ciencia ni una "filosofía de la existencia”, sino una metafísica en el sentido fuerte de la palabra. Esta, más que de Blanchot, es una advertencia hecha por Karl Jaspers, que no debemos olvidar. ¡Pero, mal que le pese a su hermana, o al Lukács de El asalto a la razón, Nietzsche no tiene nada que ver ni con el judaísmo ni con el antisemitismo! Y vaya si a ambos les pesa: para divinizarlo o para satanizarlo, hay que forzar adecuadamente las cosas. Blanchot lo dice con su peculiar elegancia: "Quien desee la ciencia, también debe querer las consecuencias de la ciencia, y en definitiva debe querer el nihilismo" (187).

El uso de este pensador "tímido y silencioso" no debe hacernos caer en aquello que precisamente denunció. Cultivar su mito es contribuir a ello. Definiciones del nihilismo hay en Nietzsche para escoger, y el escritor sería el último en eliminarlas una a una. Pero su gran aporte sería este: el conocimiento es fundamentalmente peligroso. ¿Nihilista o trágico? ¡Autocontradictorio! Que el reverso de la ciencia sea el nihilismo no es aún algo libre de sospecha. ¿Qué quiere decir Nietzsche con ello? ¿Que la ciencia es nihilista o que solo sus consecuencias lo son? Determinemos su carácter aparentemente autocontradictorio. 


\section{VI}

Quizá no sea propiamente antifilosófica, pero la posición de Blanchot, representante atípico de la french theory (sus textos sobre Nietzsche se inscriben al calce de Foucault, Deleuze, Granier y Derrida) es indudablemente antiplatónica. Aunque eso de "anti" con seguridad no es en todo rigor aplicable a su pensamiento de lo Neutro. La ciencia es la negación activa (o, mejor, reactiva) de lo trágico, pero es trágica en sus efectos. ¿Es tal la hipótesis? Si es así, todo el pensamiento de Blanchot posee una coloración que no es ni optimista ni pesimista. Ello es lógico si consideramos que la ciencia, si quiere construir todo de nuevo, ha de tener también el poder de destruirlo. Pero, ¿qué pasa con el hombre de esta transformación? ¿Cambia? ¿Se encuentra a la altura de las nuevas circunstancias? Escasamente. Hay, al contrario, un empequeñecimiento. El hombre que conoció Nietzsche es anodino e insuficiente. Forma parte del suceso sin muy bien percatarse. El de hoy es un ejemplar "que se cree definitivo, estable dentro de su naturaleza, feliz en el pequeño círculo de sí mismo, entregado al ánimo de venganza, mientras, empujado por la fuerza impersonal de la ciencia y por la fuerza propia del acontecimiento que le libera de los valores, tiene un poder que le supera sin que intente superarse él mismo en ese poder"(192). En otros términos, si no es un burócrata empedernido, es un niño que juega con fuego.

Lo más fácil sería tomar partido por una concepción de lo humano que haría de este un dato invariable, pero Nietzsche decide jugársela al devenir. Tal es, de acuerdo con Heidegger, el sentido del Übermensch: no una intensificación del hombre tal como lo conocemos, sino el poder de dejar atrás esa figura anacrónica (y no poco patética). Claro que Heidegger utiliza este concepto en su ambivalencia para proponer su correspondiente crítica. El hombre, aun bajo la forma del superhombre, no deja de querer; por 
consiguiente, lo metafísico (es decir, lo violento, según Heidegger) no se le quita. El punto de no retorno es, paradójicamente, el pensamiento del eterno retorno, tal vez lo más difícil de asimilar de la doctrina de Nietzsche.

¿Podrá Superman detener el tiempo y modificar el pasado? Solo en el cine (y hacerlo es de un insuperable mal gusto). En realidad es imposible. Pero es al revés de como lo imaginábamos: el ser no puede reducirse a nada. La nada nada puede con el ser; el nihilismo es impracticable. ¡Hasta a Blanchot tal conclusión le parece una broma! Pero hay que ver. Nihilista es la confianza en el poder humano de transformar el ser; ahora bien, este poder tiene un límite absoluto que cobra forma en el pensamiento del eterno retorno. ¡Nada qué hacer! ¿Nada? Heidegger sostendrá que probablemente solo se alcance a tachar, gráficamente, al ser y a la nada. Nietzsche pulverizará, aforísticamente, a ambos. La escritura fragmentaria es, según el de Röcken, la forma en que el ser y la nada pueden en efecto ser tachados. Es, en todo caso, eso que pretende Blanchot. Pero su fragmentación se halla lejos de ser meramente superficial o formal; afecta a su naturaleza, que es jerárquica, bien merced a la dialéctica, bien gracias a la ciencia. Hay un modo de leer filosofía, y la de Nietzsche en concreto, que le achata todo el filo, la vuelve tranquilizadora y sedante. Esto significa que hay otra, o al menos otra manera de hacerla y leerla. Tendría que ser una filosofía aconceptual, porque pensar en términos de voluntad de poder, eterno retorno, superhombre, pensamiento trágico y nihilismo va a generar centros, grumos, atascos. Existe, admitido, un Nietzsche académico, sistemático, de bigotes rasurados; pero, dice Blanchot, existe también un Nietzsche deliberadamente estallado. Ni siquiera estaría convencido de que se trata de una filosofía aforística, por lo que ella resguarda, a pesar de todo, de sistemático. Nietzsche escribe fragmentos completos en sí mismos: un destello que no remite a algo estallado. Es arduo pensar por encima o por debajo del todo. 
"Lo fragmentario no precede al todo, sino que se dice fuera del todo y tras él" (199). Este decir fuera no equivale a contra-decir el todo; primero es preciso respetarlo y, ante todo, realizarlo. ¿Cómo? Sabiendo que, en rigor, no hay un "afuera” del todo: nadie, ningún ser humano puede habitar o parasitar el exterior de las palabras. Eso nos devuelve, por un lado, al pensamiento de Dios y nos hace creer en una trascendencia amigable.

Por otra parte, Nietzsche vuelve las nociones en contra de ellas mismas; nunca encontraremos definiciones dogmáticas en su doctrina. Su pensamiento es múltiple, pero todavía hay que comprobar que lo múltiple no se reduce a ser una afirmación multiplicada del Uno. Por eso es menester anular la contradicción. Por lo menos, evitar por todos los medios las trampas de la dialéctica, identificada por Blanchot con el idealismo cristiano. No es asunto de contradecir, en el sentido de refutar, a Hegel; es cuestión de otra cosa, de no hablar ni pensar como él. Es posible que se trate simplemente de aprender a interrumpir, de detener el discurso para que aflore la diferencia. Para ello, parece indispensable aliar el pensamiento con lo azaroso y aleatorio. El escritor quiere ir más allá, pues el pluralismo sigue siendo filosofía. El Uno es esa filosofía a la cual el pluralismo se contrapone. ¡Sigue siendo crítica dialéctica de la mala totalidad! Debe irse mucho más allá de Hegel, lo que significa que debe irse más allá de lo humano. De hecho, lo humano, desde Nietzsche, ni siquiera ha comenzado. Su inicio se enlaza con su fin: entrar en el ocaso no es participar de la decadencia o la degeneración sino en "la falta que se puede amar" (202), es decir, la muerte como posibilidad de una interrupción definitiva. Es la brutal diferencia entre el "hombre superior", que fracasa en cuanto alcanza su meta, y el "superhombre", que se sabe y se quiere, como Zaratustra, un puente y un ocaso. El "hombre superior" es el hombre "integral", el hombre realizado en su esencia, el hombre del Todo, el hombre logrado, serio, probo y riguroso. ¿El fin de la 
historia? ¿El fin o la recuperación de la infancia? Aquí se abre un profundo abismo.

\section{VII}

Trágica es, pues, la ausencia o la inexistencia de relación dialéctica. También es la falta o el repudio de la ciencia. En términos metafísicos, diremos, e incluso subrayaremos, que lo trágico es la insuficiencia y prepotencia imaginaria del Todo. Se puede jugar casi eternamente a la desaparición de lo indestructible, pues puede consistir en eso la desaparición del hombre. El "hombre", en cuanto esencia, resulta indestructible; pero puede desaparecer, borrarse del mapa. Trágica es, por caso, la desaparición de lo humano, o cuando menos el eclipse del humanismo. ¿Qué lo sustituye? ¿Dios? ¿La naturaleza? ¡Sería una burla seguir pensando en la historia! Se trata de la desaparición del Uno, sea Dios (y su Creación) o sea el Hombre (y su Historia). Si se hunde el Uno, el pensamiento flota un poco a la deriva. No es posible quedarse con el reverso de la metafísica, porque varios, en especial Heidegger, han mostrado que "invertir el platonismo" es exactamente lo mismo que quedarse con él sin cobrar conciencia de la inversión. Es necesario no pensar por fuera del lenguaje en general, sino a un costado de las contradicciones dialécticas en particular. No pensar teológicamente, porque tanto Hegel como la ciencia piensan así; tal sería el desafío de un pensar dionisíaco. Hablar de "lo Neutro" como centro del pensamiento de Blanchot resulta así problemático. Igualmente podría invocarse el Afuera, lo Incesante, lo Interminable, la Soledad esencial...

El rostro, según se sabe, ha sido para su amigo Emmanuel Levinas un motivo metafísico de gran aliento; para Blanchot, es más agradable hablar de su desaparición, del borramiento del propio semblante. Porque, a diferencia de su amigo judío, ha aceptado el 
desafío de Nietzsche: ¿cómo hablar (escribir) después de la revelación (oscura) del Eterno retorno y del pensamiento dionisíaco? No es sencillo. Tampoco se sabe como para qué. Tal vez baste con decir que ese pensamiento es apenas un murmullo paródico y se halla siempre por venir. Tal vez sea suficiente con decir que se trata de un pensamiento no recortado sobre la silueta de una figura iluminada por la luz solar. Su "objeto" escapa de toda objetividad. La pregunta es sencilla, pero no parece haber respuesta: ¿qué hacer con la fuerza? ¿Cómo pensarla o decirla? Nietzsche (y luego Deleuze) la conciben como pluralidad y como diferencia del múltiple. El lógos es efecto de la fuerza, pero no toda la fuerza es lógos. De ahí la dificultad de pensarla o decirla. Pero es ella misma, en cuanto diferencia, quien escribe. La metáfora de la luz es "imperialista", porque, desde Aristóteles al menos, se verifica la prioridad de la forma sobre la materia. "El nihilismo es invencible todo el tiempo en que, al someter el mundo al pensamiento del ser, acojamos y busquemos la verdad a partir de la luz de su sentido, pues es quizá en la luz misma en donde él se disimula" (211). Allí se cifra buena parte de la intuición blanchotiana: en esa sospecha ante una sencillez y una inmediatez que más bien engańan. En suma, caricaturizando a lo Desconocido, la luz nos propone un escenario demasiado ad hoc para nuestras evoluciones de circo. ¿Nunca podremos permitir que lo desconocido permanezca desconocido? No, por ir al tópico, meramente ignorándolo. Ese modo diferente de pensar pasa por la afirmación del azar, por una palabra sin discurso. ¡Que el enigma no sea reducido a simple adivinanza o vulgar acertijo! Por supuesto, debe impedirse que amanezca como un problema sola y exclusivamente teórico. Diré, entre paréntesis, que Blanchot, como el rock progresivo, de pronto suena demodée. No en balde son de la época (La conversación infinita es de 1969 y La amistad de 1971). Lo Neutro tiene el efecto especial de un disco rayado. Si es verdad que la diferencia es aquello que escribe, ¿por qué da 
a fin de cuentas una sensación tan desleída? ¿Por qué da la impresión de escribir con lejía? El episodio sobre Nietzsche termina con una doble interrogante: ¿El mundo? ¿Un texto? Parece llevar el pensamiento 68 a un límite absoluto, a un ya-no-más incapaz de sacarle la vuelta. ¿En qué punto estamos? ¿Dónde encallamos, si es que alguna vez salimos del puerto? Blanchot transita de la extrema derecha a la extrema izquierda, y eso no es un puro dato biográfico. Es lo que ocurría en efecto al borrarse a sí mismo. El "espacio literario" se abre a condición de una detención, de un "arresto" de muerte, pero, como ha observado Giorgio Agamben, ello obedece justamente a la imposibilidad de morir.

Seguimos sin contestar la pregunta: ¡a dónde hemos llegado? Blanchot es un escritor que, antes o en lugar de decir algo digno de reflexión o de repetición, invita. Invita a escribir... o a no decir nada por decir. Está siempre desapareciendo, pero detrás de sus amigos escritores: Antelme, Foucault, Nancy, Des Forêts, Mascolo, Duras, Nadeau, Derrida, Levinas, Laporte... Es una escritura neutra, seguramente, pero, como la de Deleuze, hace escribir, obliga a ello. Una tragedia, una escritura trágica, seguramente, pero gozosa. No es viable, al respecto, comenzar por el Cogito, ni siquiera tomando en cuenta sus fisuras congénitas. Albert Camus lo sustituye sin complejos por el rebelde, por el grito: "me rebelo, luego somos". Sigue dándose la luz del Cogito, sin embargo. Por lo demás, hay que preguntarse si son igual de transparentes el sujeto negativo de la esclavitud y el sujeto afirmativo del mito (sea el de Sísifo o sea otro). Persiste en Camus, presunto existencialista, la inundación hegeliana. Es su calificación del Absurdo: una fase transitoria de la razón. Es una "apacible victoria lógica” que hace callar o disimular al Absurdo o a lo que existe detrás de esta palabra tal vez demasiado clara, máscara del nihilismo (229). En este punto, la postura del escritor puede sorprender: tal vez no sea cuestión de ponerse siempre en guardia contra el nihilismo, sino, con malicia o picardía, 
hacerlo nuestro aliado. ¿Sería posible? ¿No será otro de sus ardides? En suma, ¿qué es el nihilismo sino el terrible y tentador reino del para qué? Sísifo es más trágico que el rebelde; digamos que es más rebelde que quien así se presenta. Según el propio Camus, el rebelde hace de la muerte del otro un medio, mientras que la muerte de sí no es medio para ninguna cosa. ¡Menuda diferencia!

\section{VIII}

Advertimos que Antígona delinea de modo definitivo el perfil de lo trágico: la muerte es inconmensurable con la vida, luego es inútil tratar de hacer de ella un medio. Pero en esto es semejante al lenguaje: querer hacer de él solamente un elemento del diálogo, tal como pretende la dialéctica, es grotesco. Hablando de Kafka, se dirá que el mal se extingue conversando, pero es preciso percatarse de que esa conversación ya es el mal. Es absurdo creer que el absurdo es eliminable por la razón; sería algo así como convencer a Sísifo de que lo que hace no tiene sentido (y que solo por eso va a dejar de hacerlo). Infernal, para Maurice Blanchot, lo intuimos más que saberlo positivamente, es el no poder morir, el no cesar, lo interminable. Lo peor es no poder salirse del surco. ¡Dejara de ser amigo de Levinas! Llega a ser exasperante, si no el contenido, sí el estilo. "Experiencia de la no experiencia, olvido de la falta de olvido", etc. Llega, tras más de 250 páginas, a ser muy fastidioso, por más que se tropiece uno con pequeñas pero valiosas perlas en el camino. Llega, en fin, no a ser trágico sino desesperante (a menos que la desesperación sea antesala de la tragedia); ¿eso buscaba el escritor? Porque si no, vaya si lo consigue. Es un entretenimiento infinito, un mantenerse sin descanso y sin sentido atentos a una conversación que se solaza o se ocupa principalmente en dar vueltas sobre sí. Por higiene, es muy probable que nos encontremos en el punto de volver atrás. ¡Comencemos de nuevo! 


\section{Bibliografía}

Agamben, Giorgio, 2007, La potencia del pensamiento, Anagrama, Barcelona.

Bataille, Georges, 1988, Lascaux o el nacimiento del arte, Alción, Córdoba.

Bident, Christophe, 2003, "La part de l'autobiographie", Magazine Littéraire, núm. 424, París, octubre, pp. 25-33.

Blanchot, Maurice, 2011, La Amistad, Trotta, Madrid. , 2008, La conversación infinita, Arena Libros, Madrid.

Camus, Albert, 1969, El hombre rebelde, Aguilar, Madrid.

Hegel, G. W. F., 1967, La fenomenología del espiritu, Fondo de Cultura Económica, México.

Heidegger, Martin, 2004, Carta sobre el "humanismo", Alianza, Madrid.

Levinas, Emmanuel, 1988, Totalidad e infinito, Sígueme, Salamanca.

Nietzsche, Friedrich, 2010, Obras completas III, Tecnos, Madrid.

Weil, Simone, 2017, La persona y lo sagrado, Hermida, Madrid. 